\title{
Adensamento institucional e outreach: um breve balanço do BRICS
}

\author{
Institutional consolidation and outreach: \\ a brief review of BRICS
}

\author{
DOI: $10.21530 /$ ci.v13n3.2018.727
}

\author{
Leonardo César Souza Ramos ${ }^{1}$ \\ Ana Elisa Saggioro Garcia ${ }^{2}$ \\ Diego Pautasso ${ }^{3}$
}

Fernanda Cristina Ribeiro Rodrigues ${ }^{4}$

\section{Resumo}

O artigo apresenta uma discussão sobre os processos de institucionalização e expansão do BRICS ao longo de suas nove cúpulas, destacando duas áreas temáticas: (i) economia política internacional - particularmente desenvolvimento internacional; e (ii) segurança internacional. A hipótese é a de que o BRICS vem passando por um processo de adensamento institucional, cuja maior expressão foi a criação do Novo Banco de Desenvolvimento (NBD) e do Arranjo Contingente de Reservas (ACR). Nesse processo, embora os temas de segurança internacional

1 Doutor em Relações Internacionais. Professor do Departamento de Relações Internacionais - PUC Minas. Lidera, junto com o professor Javier Vadell, o Grupo de Pesquisa sobre Potências Médias (GPPM). É membro das seguintes associações: Associação Brasileira de Relações Internacionais (ABRI), International Gramsci Society (IGS e IGS Brasil) e Associação Kuyper para Estudos Transdisciplinares (AKET). É coordenador da área temática de Economia Política Internacional - ABRI (2015-2016; 2017-2018).

2 Doutora em Relações Internacionais. Professora Relações Internacionais - UFRRJ. Professora do Departamento de História e Relações Internacionais na Universidade Federal Rural do Rio de Janeiro (UFRRJ). Coordenadora do Laboratório Interdisciplinar de Estudos de Relações Internacionais (LIERI/UFRRJ). Pesquisadora colaboradora do Instituto Políticas Alternativas para o Cone Sul (PACS). Foi pesquisadora visitante na York University, Canadá. Tem experiência na área de Economia Política Internacional.

3 Mestre e doutor em Ciência Política também pela UFRGS. Atualmente é professor de Geografia do Colégio Militar de Porto Alegre. É colaborador da Especialização em Estratégia e Relações Internacionais Contemporâneas, bem como membro do NERINT e do CEBRAFRICA na UFRGS. Atua nas áreas de pesquisa de Relações Internacionais e Geografia Política, sobretudo em temas como BRICS, China e relações Sul-Sul.

4 Mestranda em Relações Internacionais pela PUC-MG. Pós-Graduada em Gestão de Negócios pela Fundação Dom Cabral. Professora do Departamento de Administração e Comércio Exterior no Centro Universitário UNA. É membra da Associação Brasileira de Relações Internacionais (ABRI) e do Grupo de Pesquisa sobre Potências Médias (GPPM).

Artigo submetido em 06/11/2017 e aprovado em 03/04/2018. 
ganhem importância crescente, isso se deve às transformações na geopolítica do capitalismo contemporâneo. Além disso, há também um concomitante processo de outreach do BRICS. Nesse contexto, distintos padrões de adensamento institucional do arranjo podem ser notados. Concluiu-se que tanto o destaque das questões de segurança internacional quanto o processo de outreach com relação a outros países sofre uma influência direta do país que hospeda a cúpula. Ainda assim, o adensamento institucional ocorre em larga medida nas questões associadas à economia política internacional e, em particular, à questão do desenvolvimento internacional - uma espécie de "caminho de menor resistência" - embora não se deva perder de vista os avanços ocorridos nas últimas cúpulas nas questões de segurança internacional.

Palavras-chave: BRICS; segurança internacional; Novo Banco de Desenvolvimento; Sociedade Civil; Outreach

\begin{abstract}
The article aims at present a discussion about the processes of institutionalization and expansion of the BRICS through its eight summits. It will be emphasised two issue areas: (i) international political economy - particularly international development - and (ii) international security. The hypothesis is that the BRICS forum has passed through an institutional thickening process - see the New Development Bank and the Contingent Reserve Agreement. In such process, despite the increasing relevance of the international security issues, this occurs because of the geopolitical transformation on the contemporary capitalism. Besides that, there is also a BRICS outreach process. In such context, there are different patterns of institutional thickening directly related to the role of BRICS at the world order. We conclude that the emphasis on the international security issues and the outreach to other states is directly influenced by the host countries, generating a pat dependence to the BRICS and impacting the institutional thickening. Even so, through BRICS history its institutional thickening occurs mainly on IPE issues, particularly on international development - a kind of "path of least relevance".
\end{abstract}

Keywords: BRICS; International Security; New Bank of Development; Civil Society; Outreach

\title{
Introdução
}

Há mais de 10 anos, em 23 de setembro de 2006, os chanceleres de Brasil, Rússia, Índia e China se reuniram à margem da $61^{\text {a }}$ Assembleia Geral das Nações Unidas, naquele que pode ser considerado o pontapé inicial que levaria à criação do BRICS. O grupo, que surge a partir de um acrônimo originário do mercado financeiro, assumiu características e relevância que sobrepujaram tal origem. 
Na verdade, uma análise mais apropriada do BRICS passa, necessariamente, por um entendimento desse arranjo a partir de uma abordagem que vá além do prisma da ideia de "mercados emergentes" apenas. É preciso levar em consideração os processos mais amplos de institucionalização e expansão do BRICS, vistos a partir das relações do BRICS com os complexos fenômenos da ordem mundial, para que se possa explorar criticamente os limites do potencial transformador-subversivo do BRICS com relação à ordem mundial.

Nesse sentido, o presente artigo apresenta uma discussão sobre tais processos ao longo de suas cúpulas, destacando duas áreas temáticas: (i) economia política internacional - particularmente a esfera do desenvolvimento internacional; e (i) segurança internacional. A hipótese assim é de que, em ambas áreas temáticas, o BRICS vem passando, desde sua origem, por um processo de adensamento institucional, cuja maior expressão foi a criação do Novo Banco de Desenvolvimento (NDB) e do Arranjo Contingente de Reservas (ACR). Nesse processo, nota-se que, embora os temas de segurança internacional ganhem importância crescente, isso se deve em larga medida às transformações na geopolítica do capitalismo contemporâneo. Além disso, nota-se também um concomitante processo de outreach do BRICS, que por sua vez apresenta uma série de contradições entre os atores envolvidos. Nesse contexto, distintos padrões de adensamento institucional do arranjo podem ser notados, diretamente relacionados ao papel desempenhado pelo BRICS na ordem mundial.

Em termos metodológicos, para a validação ou não da hipótese acima, será feito um estudo de caso associado ao process tracing (BENNET, 2010; BEACH; PEDERSEN 2013). Ou seja, será feito um estudo do BRICS bem como de alguns dos múltiplos mecanismos causais a ele associados a fim de, assim, melhor compreender o delineamento do processo de constituição de tal arranjo, contribuindo, dessa forma, para a produção de inferências causais acerca do caso em questão. Mecanismos causais aqui são entendidos como algo constitutivo do nível ontológico das relações sociais (BENNETT, 2013), o que nos afasta do positivismo e nos coloca próximos a interpretações realistas científicas e realistas críticas acerca dos conceitos de "mecanismo causal”, “causa”, “causalidade” e "causação”.

Os mecanismos causais multiníveis são fundamentais para que se possa compreender os rumos do BRICS desde seus primórdios. Assim, são destacados nesta pesquisa os seguintes mecanismos causais: (i) as relações regional/global presentes na construção da agenda de inserção internacional dos países do BRICS; (ii) as relações entre o BRICS e a ordem geoeconômica mundial; (iii) em menor 
escala, mas não menos importante, as relações entre BRICS e as forças sociais. É a partir da identificação desses mecanismos causais - que muito além de serem variáveis, são entidades ontologicamente constitutivas do processo de construção do BRICS - que ganham significado inferencial (i) os processos de adensamento institucional nas áreas de economia política internacional (desenvolvimento internacional) e segurança internacional e seus respectivos mecanismos de path dependence; e (ii) processos multinível de outreach.

Para tal empreitada, a ênfase será dada na análise qualitativa dos documentos produzidos pelas cúpulas, o que será feito em estreita relação com a análise da literatura existente sobre o tema, bem como com a análise da conjuntura internacional no período em questão. Primeiro, será apresentado um histórico do BRICS a partir de suas cúpulas. Em seguida, será discutido o processo de outreach do BRICS. Desde a II Cúpula em Brasília, em 2010, há menção explícita ao processo de outreach do BRICS, intimamente relacionado a uma expansão das áreas de interesse do grupo. Não obstante, no presente artigo, a ideia de outreach focará explicitamente em dois elementos: (i) o convite a outros Estados para participar das cúpulas; (ii) o engajamento das forças sociais no processo, particularmente expresso no fórum de empresários e nas reuniões dos movimentos de contestação da sociedade civil. Em terceiro lugar, serão explorados os limites do processo de ascensão do BRICS como potencial polo “contra-hegemônico”, para, por fim, serem feitas algumas considerações finais e suas relações com a hipótese apresentada.

\section{BRICS: De Ecaterimburgo a Xiamen}

As crises econômicas que se acumulam desde meados dos anos de 1990 deixaram evidente que a gestão da ordem mundial não poderia continuar desconhecendo os avanços dos países emergentes, que até então não participavam do G8 (G7 + Rússia). Desse modo, no final dos anos de 1990, foi criado o G20 (que até 2008 não incluía uma reunião de chefes de Estado), após a crise asiática. E, a partir do início dos anos 2000, Brasil, Índia, China e África do Sul, além do México, passam gradualmente a serem convidados como observadores do G8 (a ideia de G8 +5), sem contudo participar dos debates sobre os rumos da economia mundial. Paralelamente, em 2003, é criado o fórum IBAS (Índia, Brasil e África do Sul) e, em 2006, ocorre a primeira reunião dos ministros de relações exteriores de Brasil, Rússia, Índia e China. Assim, a história do BRICS tem sido marcada por 
um aprofundamento do grau de institucionalização do arranjo, desde a I Cúpula do BRIC, em junho de 2009, em Ecaterimburgo, Rússia.

A I Cúpula foi marcada pelos resultados da cúpula do G20, refletindo o comprometimento do grupo com as decisões acordadas, bem como apontando para o que seria a cooperação do grupo na cúpula seguinte do G20. Além disso, o BRIC também enfatizou a importância da reforma das instituições financeiras internacionais (IFI), a fim de aumentar a participação das potências médias emergentes na ordem internacional (MINISTÉRIO DAS RELAÇÕES EXTERIORES, 2009). A II Cúpula do BRIC ocorreu em Brasília, em 2010, e lidou com uma série de temas - apesar do destaque para as questões concernentes à governança global e ao comércio e às finanças internacionais. Tal cúpula se destaca pelo apoio à reforma da ONU, pela ênfase na importância da estabilidade do sistema monetário internacional e pela defesa de uma solução para o problema da crise de legitimidade das organizações internacionais (MINISTÉRIO DAS RELAÇÕES EXTERIORES, 2010). Em 2011, em Sanya, ocorreu a III Cúpula do BRICS. Dois pontos de destaque dessa cúpula foram (i) a inclusão da África do Sul no BRICS e o fato de que, naquele momento, (ii) todos os países partícipes do BRICS também se encontravam no Conselho de Segurança da ONU, o que fez com que a cúpula desse grande destaque para as questões de segurança, como a Primavera Árabe. Nesse ponto, cumpre destacar que, pela primeira vez, houve referência explícita na declaração final à reforma da ONU (MINISTÉRIO DAS RELAÇÕES EXTERIORES, 2011, "para"8). Além disso, foi reafirmada a importância do G20 na arquitetura financeira internacional e a necessidade de se concluir a Rodada Doha (MINISTÉRIO DAS RELAÇÕES EXTERIORES, 2011). A IV cúpula do BRICS, em Nova Deli, 2012, apresentou um novo fato: pela primeira vez, foi discutida a possibilidade de se criar, a partir do BRICS, um novo banco multilateral de desenvolvimento, o que culminou no compromisso de examinar a viabilidade de tal banco. Além disso, a declaração final reiterou a importância da cooperação internacional, embora tenha destacado a necessidade da reforma das IFI, para que a importância sistêmica dos países do BRICS fosse reconhecida institucionalmente (MINISTÉRIO DAS RELAÇÕES EXTERIORES, 2012).

A V cúpula do BRICS ocorreu em 2013, em Durban, e fechou o primeiro ciclo das cúpulas, além de ser um marco na busca sul-africana por uma maior projeção internacional (ANDREASSON, 2011). Essa cúpula deu destaque às relações dos BRICS com países africanos e, assim como nas cúpulas anteriores, foi reafirmado o comprometimento com o multilateralismo e a busca por uma governança global 
mais democrática. Nesse caso, foi destacada a reforma das IFI, em especial do sistema de cotas do FMI, conforme acordado em 2010 (MINISTÉRIO DAS RELAÇÕES EXTERIORES, 2013, "para"13). Também foi destacado o comprometimento do BRICS com a conclusão da Rodada Doha, o apoio para que Brasil, Índia e África do Sul tivessem um papel mais proeminente na ONU e, por fim, o BRICS manifestou seu apoio para que o diretor geral da OMC representasse os países em desenvolvimento. Tal questão é relevante, já que o brasileiro Roberto Azevêdo foi eleito para o cargo em questão.

Foi também criado um fundo de reserva de US $\$ 100$ bilhões, o que "ajudaria os países do BRICS a evitar pressões de liquidez de curto prazo" (MINISTÉRIO DAS RELAÇÕES EXTERIORES, 2013, "para”10), dando continuidade aos acordos assinados em 2012 entre os bancos de desenvolvimento dos países do BRICS (MINISTÉRIO DAS RELAÇÕES EXTERIORES, 2012). Por fim, foi anunciada a criação de um banco de desenvolvimento do BRICS, que deveria buscar

recursos para projetos de infraestrutura e de desenvolvimento sustentável nos BRICS e em outras economias emergentes e países em desenvolvimento, para complementar os esforços já existentes de instituições financeiras multilaterais e regionais para o crescimento global e o desenvolvimento (BRICS 2013, "para”9)

- dando sequência, assim, à discussão de Nova Deli.

A VI cúpula do BRICS, em Fortaleza, 2014, deu início ao segundo ciclo das cúpulas. Em um dos momentos mais relevantes na história do BRICS e de seu processo de adensamento institucional, foi assinado o "Acordo constitutivo do Novo Banco de Desenvolvimento (NDB), com o propósito de mobilizar recursos para projetos de infraestrutura e desenvolvimento sustentável nos BRICS e em outras economias emergentes e em desenvolvimento" (MINISTÉRIO DAS RELAÇÕES EXTERIORES 2014a, "para"11). O banco teria um capital inicial autorizado de US $\$ 100$ bilhões - com um capital inicial subscrito de US $\$ 50$ bilhões. Além disso, também foi estabelecido o Arranjo Contingente de Reservas do BRICS (ACR) US $\$ 100$ bilhões - e assinado o Memorando de Entendimento para Cooperação Técnica entre Agências de Crédito e Garantias às Exportações dos BRICS. O primeiro "terá efeito positivo em termos de precaução, ajudará países a contrapor-se a pressões por liquidez de curto prazo" e o segundo "aperfeiçoará o ambiente de apoio para o aumento das oportunidades comerciais" entre os países do BRICS (MINISTÉRIO DAS RELAÇÕES EXTERIORES, 2014a, "para”13 e "para”14). 
A VII Cúpula dos BRICS, que ocorreu em Ufá, 2015, foi acompanhada por grandes expectativas. O aprofundamento da cooperação econômica foi discutido no marco da "Estratégia para uma Parceria Econômica do BRICS", que embora tenha destacado a importância da cooperação em diversas áreas, não avançou objetivamente (MINISTÉRIO DAS RELAÇÕES EXTERIORES, 2015, “para”17). Com relação à cooperação comercial, financeira e de investimentos intra BRICS, nota-se um avanço a partir do aprofundamento do diálogo entre as "Agências de Crédito às Exportações dos BRICS", do papel do "Mecanismo de Cooperação Interbancária do BRICS", da implementação do "Marco do BRICS de Cooperação em Comércio e Investimentos" e da importância de um estudo acerca da viabilidade do "uso mais amplo de moedas nacionais no comércio mútuo” (MINISTÉRIO DAS RELAÇÕES EXTERIORES, 2015, "para"13, "para”14, "para”23 e "para”24).

Contudo, ficou claro que a prioridade da cúpula seria o NDB e o ACR. Nesse sentido, foram discutidos os detalhes sobre a entrada em vigor desses novos arranjos institucionais. Ora, isso tem relação direta com a situação de crescimento econômico negativo de Brasil e Rússia naquele momento: para o Brasil, o NDB deveria favorecer investimentos nas áreas de energia e infraestrutura; já a Rússia via no NDB a grande oportunidade de atrair o capital chinês. Além disso, foi apresentada na cúpula a proposta de cooperação entre o NDB e o recém-criado Banco Asiático de Investimento em Infraestrutura (BAII) ${ }^{5}$ o que seria importante no financiamento dos projetos de infraestrutura vinculados à Nova Rota da Seda (MINISTÉRIO DAS RELAÇÕES EXTERIORES, 2015, “para”15; DANÍLOVA, 2015). Assim, apesar do BAII ter, em alguma medida, eclipsado a importância do NDB, isto pode significar, nos médio e longo prazos, menor concorrência e, consequentemente, maior disponibilidade de recursos do NDB para Brasil e África do Sul.

Já era esperado que em Ufá fosse seguida uma tendência das cúpulas anteriores de direcionamento da agenda por parte do país anfitrião. Nesse caso, era esperada uma aproximação entre BRICS, Organização para Cooperação de Xangai (OCX) e União Econômica Eurasiática (UEE), o que contribuiu tanto para as discussões na área econômica quanto na área da segurança internacional. Assim, se destacam nas discussões sobre segurança: (i) a menção explícita à importância do respeito à soberania e não intervenção em vários casos (especialmente Afeganistão, Iraque e Síria); (ii) a existência de um espaço significativo para as questões de

5 O BAII foi criado no mesmo ano que o NDB. Entretanto, ele é composto por 57 membros fundadores (alguns deles aliados históricos dos EUA, como Inglaterra, Alemanha e França) e tem clara dominação da China, que detém o poder de veto, a presidência do banco e a localização de sua sede, em Pequim. 
segurança e um aumento exponencial de referências explícitas aos problemas de segurança no continente africano - o que reflete a preocupação dos países do BRICS com a estabilidade da região (RAMOS et al., 2012). A despeito das críticas ao ordenamento vigente e à ação das potências tradicionais, a estratégia de não confrontação permanece, e os arranjos multilaterais existentes tiveram sua importância reafirmada (MINISTÉRIO DAS RELAÇÕES EXTERIORES, 2015, "para"11, "para"18, "para"19, "para"26 e "para"66).

A Declaração Final de Goa (2016) reiterou que a paz sustentável requer a construção de uma "ordem internacional multipolar equitativa e democrática" com um papel central da ONU. Mas, ao mesmo tempo que destaca o papel da ONU, o documento reivindica a reforma do Conselho de Segurança, de modo a torná-lo mais representativo e eficiente (BRICS, 2016, "para"6-8) - tema este que continua a ter força por pressão da Índia e África do Sul, apesar do esforço menos significativo do atual governo brasileiro.

Outros pontos importantes foram o apoio à recente decisão do grupo de trabalho do Comitê para a Utilização Pacífica do Espaço Exterior (COPUOS) da ONU sobre a intenção de criar um plano-quadro de longo prazo de sustentabilidade no espaço até 2018 (MINISTÉRIO DAS RELAÇÕES EXTERIORES, 2016, “para”55-56) e o apoio à iniciativa russa para elaboração de uma convenção internacional de proibição do terrorismo químico e biológico, a partir da cooperação em nível bilateral e internacional (MINISTÉRIO DAS RELAÇÕES EXTERIORES, 2016, “para”58). Fica claro, nesse caso, os interesses da diplomacia russa com relação ao combate ao separatismo checheno e a grupos extremistas internacionais, como aqueles que lutam na Síria contra o governo de Assad.

A Síria, aliás, também recebeu destaque no documento final. A Rússia, como principal membro do BRICS envolvido no assunto, fez constar no documento a posição que sua diplomacia vem defendendo: a construção da paz através de um diálogo nacional inclusivo e um processo político liderado pelo governo sírio e baseado no Comunicado de Genebra de 30 de Junho de 2012, nos termos da resolução 2254 e 2268 do Conselho de Segurança da ONU, bem como no combate aos grupos terroristas como ISIS e Jabhat al-Nusra (MINISTÉRIO DAS RELAÇÕES EXTERIORES, 2016, "para"14; PAUTASSO; ADAM; LIMA, 2015). Dois outros temas de segurança foram destacados. Primeiro, o conflito palestino-israelense; segundo, o apoio ao governo afegão para construir a reconciliação nacional (MINISTÉRIO DAS RELAÇÕES EXTERIORES, 2016, “para”15-16). 
Com relação ao processo de institucionalização do BRICS, destacam-se a assinatura do Memorando de Entendimento para o Estabelecimento de uma Plataforma de Pesquisa Agrícola do BRICS (BRICS, 2016, "para"86); a primeira reunião do grupo de trabalho do BRICS sobre contraterrorismo, em 14/09/2016 (MINISTÉRIO DAS RELAÇÕES EXTERIORES, 2016, "para”60); os avanços operacionais do NDB; o início das negociações sobre a proposta de criação de uma agência de risco (rating) do BRICS (MINISTÉRIO DAS RELAÇÕES EXTERIORES, 2016, "para"44); a criação de uma plataforma de discussão conjunta entre as Agências de Crédito às Exportações dos BRICS para cooperação comercial entre os países do BRICS (MINISTÉRIO DAS RELAÇÕES EXTERIORES, 2016, "para”13); e o estabelecimento de um Comitê de Cooperação Alfandegária do BRICS, no marco da Estratégia para uma Parceria Econômica do BRICS, estabelecida na VII Cúpula, em Ufá (MINISTÉRIO DAS RELAÇÕES EXTERIORES, 2015, “para”17; 2016, “para”48).

A IX Cúpula ocorreu em Xiamen (2017), com destaque para 3 documentos assinados: (i) Plano de Ação do BRICS para a Cooperação para a Inovação (2017-2020); (ii) Estrutura Estratégica da Cooperação Aduaneira do BRICS; (iii) Memorando de Entendimento entre o Conselho Empresarial do BRICS e o Novo Banco de Desenvolvimento sobre Cooperação Estratégica. Foram adotadas iniciativas para a promoção futura do desenvolvimento dos Mercados de Títulos em Moeda Local dos países do BRICS, bem como para o estabelecimento de um Fundo de Títulos em Moeda Local do BRICS (BRICS, 2017, "para”10), além do "progresso na conclusão dos Memorandos de Entendimento entre os bancos nacionais de desenvolvimento dos países do BRICS sobre linha de crédito em moeda local interbancária e sobre cooperação interbancária na área de classificação de crédito" (BRICS, 2017, "para”11). Menção foi feita aos avanços do NDB, particularmente com relação à criação do Centro Regional do NDB na África do Sul - no caso, o primeiro escritório regional do Banco (BRICS, 2017, "para”31). Com relação ao ACR, foi acordado o Sistema de Intercâmbio de Informações Macroeconômicas (SEMI) do ACR (BRICS, 2017, "para”30).

$\mathrm{Na}$ área da segurança internacional, foram condenadas as "intervenções militares unilaterais", em referência a certas declarações do presidente estadunidense Donald Trump. Tópicos como terrorismo, Síria e outros conflitos internacionais também foram mencionados, bem como certas discussões sobre a implantação dos Padrões Internacionais de Combate à Lavagem de Dinheiro e ao Financiamento do Terrorismo e Proliferação no FATF (BRICS, 2017, "para”38, "para”11). Pela primeira vez, a China reconheceu como terroristas grupos baseados no Paquistão 
- Lashkar-e-Taiba, Jaish-e-Mohammad e a rede Haqqani -, o que foi visto como uma vitória por parte da diplomacia indiana. Além disso, destacam-se a $7^{a}$ Reunião de Assessores de Segurança Nacional do BRICS, realizada em 27 e 28 de julho de 2017, em Pequim; a segunda reunião do Grupo de Trabalho sobre Terrorismo do BRICS, realizada em Pequim, em 18 de maio de 2017; bem como a extensa presença das questões de segurança na declaração final.

\section{A expansão do BRICS: O processo de outreach}

Além dos avanços institucionais, destaca-se também o processo de outreach do BRICS, que desde a II Cúpula em Brasília, em 2010, é mencionado explicitamente nos documentos finais. No que concerne à expansão das relações do BRICS com outros Estados, nota-se uma importância significativa do país anfitrião, que não apenas direciona a agenda das cúpulas, mas também faz os convites para os países não membros. Nesse sentido, um ponto de inflexão é a V Cúpula, em Durban: a partir dela, em quase todas as cúpulas houve um engajamento mais robusto do BRICS com outros países: em Durban (2013), houve uma reunião com líderes africanos - em clara consonância com os interesses sul-africanos na região; em Fortaleza (2014), houve uma sessão conjunta com os líderes dos países sul-americanos, expressão dos interesses brasileiros com relação à região e, particularmente, com relação à UNASUL; em Ufá (2015), houve uma reunião com os chefes de Estado e de governo dos países da UEE e da OCX, bem como com os chefes de Estados observadores da OCX - algo claramente convergente com os objetivos de inserção internacional da Rússia em um contexto de conflito na Ucrânia, com amplas repercussões internacionais; em Goa (2016), foi organizada a cúpula BRICS-BIMSTEC - Iniciativa da Baía de Bengala para a Cooperação Econômica e Técnica Multissetorial -, da qual participam Bangladesh, Butão, Índia, Myanmar, Nepal, Sri Lanka e Tailândia. Nesse encontro, foram tratadas questões sobre cooperação nas áreas de comércio e investimentos (MINISTÉRIO DAS RELAÇÕES EXTERIORES, 2016, "para"5) e, além disso, houve a inclusão do tema do combate ao terrorismo, o que pode ser interpretado como um ganho da diplomacia indiana em sua busca por isolar o Paquistão (SAJJANHAR, 2016); e em Xiamen (2017), a China deu início ao que chamou de cooperação BRICS Plus, da qual participaram Cazaquistão, Egito, Quênia, Indonésia, México, Tadjiquistão e Tailândia (BRICS, 2017, "para"6). 
Aqui cabe uma consideração: os países membros do BRICS têm interesse fundamental em garantir sua liderança em âmbito regional. Seu protagonismo na arena global depende, em grande medida, da capacidade de liderar respectivos processos regionais de integração ${ }^{6}$. Nota-se que suas regiões e os correspondentes blocos econômicos são historicamente uma prioridade na agenda de todos os cinco integrantes.

Objetivamente, a China confere grande relevância à OCX, à Associação das Nações do Sudeste Asiático + China (ASEAN + 1) e demais agendas regionais, incluindo a delicada questão securitária referente às disputas territoriais no mar do Sul da China. A Rússia busca relançar um bloco, a UEE, em parte devido à inoperância da Comunidade dos Estados Independentes (CEI), lançada logo após o colapso da URSS. A África do Sul dá forte ênfase à Nova Parceria para o Desenvolvimento da África (NEPAD) e à Comunidade para o Desenvolvimento da África Austral (SADAC). E, por fim, o Brasil tem historicamente um papel de liderança na América do Sul, dando prioridade ao MERCOSUL, combinado com a criação da UNASUL na última década (situação essa que muda, no caso, a partir do governo Temer). Em suma, isso explica o interesse em envolver os demais vizinhos nas cúpulas do BRICS, ao mesmo tempo que confere escopo de influência cada vez mais global ao agrupamento - além de, indiretamente, fortalecer as organizações regionais em questão. Nesse caso, seguramente tensões podem aparecer: particularmente, as negociações em torno do "BRICS Plus" têm despertado certo incômodo e desconfiança em certos setores indianos, que veem tais declarações como uma tentativa chinesa de tornar o BRICS uma organização cada vez mais alinhada com os interesses chineses de inserção internacional (Neelakantan, 2016).

Outra forma de outreach diz respeito ao envolvimento de outros atores para além dos Estados do BRICS. Nesse caso, destacam-se aqui os atores empresariais, articulados no Conselho Empresarial dos BRICS, e os movimentos sociais, que têm desempenhado esforços de articulação e encontros fora das cúpulas oficiais. Garcia e Bond (2015) apresentam uma pertinente classificação dos posicionamentos dos atores da sociedade civil com relação ao BRICS. O BRICS from above é a posição expressada por chefes de Estado e seus aliados das elites corporativas. Esses utilizam por vezes uma retórica nacionalista e de enfrentamento às potências

6 O que não significa, necessariamente, um engajamento ativo em favor do aprofundamento desses processos de integração regional. Para uma análise recente sobre a política externa brasileira para a UNASUL, que problematiza tais questões. 
ocidentais para legitimar o avanço sobre países vizinhos para exploração de recursos naturais e força de trabalho; o BRICS from the middle é uma posição comumente vista em instâncias como o Fórum Acadêmico dos BRICS, e alguns think tanks e ONGs. Esses são esperançosos de que o BRICS possa efetivamente desafiar as injustiças globais, mas aguardam seus avanços, traçando algumas análises críticas; por fim, o BRICS from below reflete a posição de movimentos sociais de base em luta nos países, que podem criar laços comuns de luta e solidariedade transnacionais. Assim, os autores ressaltam a importância de compreender os países do BRICS para além do seu sentido estreito (como instituições de autoridade política), expresso nas cúpulas de chefes de Estado. É necessário enxergá-los em seu sentido ampliado, examinando as forças na sociedade civil que se articulam com os Estados e se institucionalizam para impulsionar e sustentar projetos (contra)hegemônicos (GRAMSCI, 1971).

Nesse sentido, podemos analisar o Conselho Empresarial do BRICS e o Foro Empresarial do BRICS como instituições do BRICS from above, que envolvem as grandes corporações multinacionais dos países do BRICS e seus principais setores econômicos. O Fórum Empresarial do BRICS ocorre desde a segunda cúpula de chefes de Estado em Brasília, em 2010, e tem lugar paralelamente a todas as cúpulas desde então. Porém, foi na cúpula de Durban, em 2013, que o fórum deu origem a um órgão mais permanente: o Conselho Empresarial do BRICS. O conselho se autodefine como uma "plataforma", que tem por objetivo "promover e fortalecer negócios, comércio e investimento" entre os cinco países, assegurar o diálogo permanente entre a comunidade empresarial e os governos e identificar problemas e gargalos a serem solucionados. Desde 2013, o conselho se organiza em grupos de trabalho por setor/indústria, sendo eles: infraestrutura (transporte, estradas, ferrovias, portos e aeroportos), manufatura (que inclui farmacêuticas, TI, entre outros), agronegócio, serviços financeiros (como bancos e seguros), energia e economia verde, e capacitação. Nesse sentido, o conselho tem encontros regulares e funciona com um papel consultivo junto aos chefes de Estado.

O primeiro relatório anual 2013-2014 do conselho, lançado em Fortaleza em 2014, estabeleceu os grupos de trabalho e as primeiras iniciativas e demandas aos governos dos países do BRICS. Segundo os empresários, os governos devem facilitar vistos, harmonizar padrões técnicos, facilitar e apoiar associações industriais, facilitar o estabelecimento de instituições financeiras e filiais nos países BRICS, e acelerar o estabelecimento do NDB para promover laços comerciais e de 
investimento. Também reforçam a necessidade de melhorar a conectividade e a logística, promover a infraestrutura e as parcerias público-privadas. Esse relatório deu especial ênfase às relações do BRICS com terceiros países, especialmente os africanos. Assim, o conselho sugeriu que os países do BRICS fortaleçam suas relações com a África do Sul e com alguns governos africanos para manter um ambiente de negócios favorável, aumentar a cooperação de agências de financiamento entre o BRICS e a África, investir nos corredores logísticos Norte-Sul na África, apoiando, nesse sentido, projetos das corporações dos países do BRICS no continente. O setor de exportação mineral é especificamente citado. O conselho espera que os países do BRICS apoiem os empresários desse setor na África, assinando contratos de longo prazo com exportadores africanos e investindo em logística. Por fim, um conselho para promover o investimento e comércio BRICS-África foi planejado (BRICS BUSINESS COUNCIL 2013/2014).

Em seu segundo relatório anual (2015-2016), lançado em Ufá, na Rússia, em 2015, o conselho estabeleceu as prioridades do setor privado para os países do BRICS. Nele são enfatizados o papel do financiamento público para bens e serviços e a importância da estabilidade macroeconômica. Nesse sentido, o NDB é elogiado e colocado como prioridade. Outras prioridades estabelecidas no documento empresarial são: o estabelecimento de um acordo de facilitação do comércio, o apoio ao comércio em moedas locais dos BRICS, a facilitação de viagens empresariais, um ambiente favorável para negócios, a cooperação entre agências regulatórias, o investimento em infraestrutura e a cooperação para projetos de infraestrutura física regional, além do reconhecimento do próprio conselho como plataforma consultiva com comunicação direta com as cúpulas presidenciais (BRICS BUSINESS COUNCIL, 2015/2016). Essa última prioridade já foi atingida. Os empresários têm efetivamente um canal direto de diálogo junto à cúpula presidencial, ao passo que representantes governamentais transitam e têm espaço privilegiado de fala na programação do Foro Empresarial, tendo sido assinado um Memorando de Entendimento entre o Conselho e o NDB em Xiamen (BRICS, 2017, "para”31).

Do "outro lado" da sociedade civil estão os encontros de movimentos sociais e ONGs, que compõem as "cúpulas dos povos" do BRICS, no sentido do BRICS from below. Segundo Waisbich (2016), apesar de frequentes obstáculos, houve um aumento significativo do envolvimento das sociedades civis do BRICS desde a entrada da África do Sul no bloco, em 2011. Esse envolvimento parte tanto de discussões no âmbito nacional, quanto de encontros internacionais. O primeiro 
desses encontros ocorreu no contexto da Cúpula de Durban, em 2013, e levou o nome de Brics from below (JANS, 2013). No ano seguinte, 2014, houve o encontro em Fortaleza (SEVERO, 2014). Já na cúpula de Ufá, houve uma inflexão: o governo russo convocou um "encontro oficial" da sociedade civil, o Civil BRICS (CIVIL BRICS, 2015), que apareceu pela primeira vez como um espaço reconhecido pela cúpula de chefes de Estado. Contudo, o espaço controlado pelo governo russo fez com que muitas ONGs não fossem convidadas, enquanto outras declinaram o convite. Em Goa, em 2016, ocorreram os dois encontros, tanto o Civil BRICS, organizado pelos governos, como o People's Forum on BRICS, organizado por movimentos sociais e ONGs indianas e internacionais (WAISBICH, 2016; PEOPLE'S FORUM ON BRICS, 2016). Já em 2017, ocorreu apenas o $3^{\circ}$ encontro do Civil BRICS em Fuzhou, em junho. Nesse caso, destaca-se o fato de que, pela primeira vez, os partidos políticos dos países do BRICS participaram do fórum. Não obstante, a ausência de diálogos anteriores entre as organizações levou a uma falta de influência dessas organizações na cúpula de Xiamen (BANDYOPADHYAY, 2017).

De modo geral, os encontros envolvem movimentos sociais, camponeses, sindicatos de base, organizações ambientalistas e feministas, especialmente do país sede da cúpula, mas também dos demais países do BRICS. Há trocas e análises sobre temas específicos locais, nacionais e globais e referentes ao BRICS e suas instituições. O tom é geralmente dado pela conjuntura dos grupos locais que auspiciam os encontros: em Durban, os grupos afetados pelo projeto de porto em South Durban; em Fortaleza, o comitê popular da Copa; em Goa, os grupos contra o turismo predatório e sexual (WAISBICH, 2016). Por outro lado, as cúpulas dos povos reúnem discussões comuns às sociedades civis do BRICS, como posicionamentos críticos quanto às consequências ambientais, sociais e econômicas de grandes projetos de infraestrutura, bem como reproduz críticas tradicionais dos movimentos antiglobalização.

\section{Expansão, adensamento e os limites da emergência}

A partir dos processos causais anteriormente identificados, nota-se alguns caminhos percorridos pelo BRICS. Primeiro, questões de segurança internacional vêm ocupando, cada vez mais, um lugar de destaque nas cúpulas. Nesse caso, a capacidade de unidade do BRICS tem sido colocada à prova, tendo em vista as transformações geopolíticas associadas às relações entre EUA e Rússia e, em menor 
grau, entre EUA e China. Particularmente, é interessante notar como a crise da Ucrânia e seus desdobramentos - por exemplo, no âmbito do G7/8 - impactaram conjunturalmente o BRICS: se, para alguns analistas, a Rússia nem mesmo deveria ser parte do BRICS, em função de uma suposta ausência de interesses e objetivos comuns (MACFARLANE, 2006; COOPER, 2006; KHALID, 2014), a partir de 2014, o que se percebe é um intenso engajamento russo que, em sua busca por manter sua esfera de influência regional, acaba influenciando significativamente a agenda do grupo (FORTESCUE, 2014). Somado a isso, nota-se uma convergência de interesses entre Índia, Rússia e China com relação ao combate ao terrorismo (NEELAKANTAN, 2016).

Olhando para essa questão dos respectivos engajamentos de cada um dos países partícipes do BRICS, Brasil e África do Sul parecem caminhar mais a reboque do grupo: a despeito de um papel mais proativo em determinados momentos da história do bloco, ambos países aparentam mais um comportamento norm-taker do que norm-maker - embora deva ser destacado que a África do Sul, em consonância com certos interesses chineses, logrou êxito significativo em colocar a África como ponto de preocupação e destaque nas declarações do grupo, mantendo assim seu objetivo de se apresentar como representante e porta-voz da África nos fóruns internacionais? ${ }^{7}$.

Nesse processo, nota-se que tanto o destaque das questões de segurança internacional quanto o processo de outreach com relação a outros países sofre uma influência direta do país que hospeda a cúpula, gerando certa dependência de trajetória para o arranjo, bem como colocando condições de possibilidade para os países anfitriões - tendo consequências para o adensamento institucional, como visto na seção anterior. Ainda assim, ao longo da história do BRICS, o adensamento institucional ocorre em larga medida nas questões associadas à economia política internacional e, em particular, à questão do desenvolvimento internacional - uma espécie de "caminho de menor resistência" (ABDENUR; FOLLY, 2015, p. 106) embora não se deva perder de vista os avanços ocorridos nas últimas cúpulas nas questões de segurança internacional. Ou seja, olhar para os avanços do arranjo em tais áreas é uma forma pertinente de identificar e relacionar os mecanismos causais subjacentes aos processos constitutivos do BRICS, bem como serve de

7 Nesse caso, há um descompasso entre a posição brasileira e os rumos atuais do BRICS: se, por um lado, o tema da reforma do Conselho de Segurança da ONU volta com força por pressão de Índia e África do Sul, por outro, o Brasil ficará de fora do Conselho de Segurança pelo menos até 2033 - já que não apresentou candidatura nos últimos anos para uma das vagas rotativas (MELLO, 2017). 
tipos de hoop tests que confirmam a relevância da hipótese apresentada acerca dos rumos do adensamento institucional do BRICS.

Não obstante, é interessante perceber que, de Ecaterimburgo a Xiamen, o avanço institucional ocorre em constante diálogo com as instituições internacionais existentes. Isso fica evidente na constante demanda pela implementação da reforma das IFI, com destaque para o FMI; a ênfase na inovação como fator chave para crescimento de médio e longo prazos e de desenvolvimento sustentável reafirmando assim a agenda do G20, expressa em 2016, em Hangzhou, bem como a importância do G20 como fórum para cooperação macroeconômica; a discussão sobre energia renovável, segurança energética e mudança climática associada aos Acordos de Paris sobre mudança climática (MINISTÉRIO DAS RELAÇÕES EXTERIORES, 2016, "para”54, "para”70 e "para”92) - além das menções feitas ao Grupo de Ação Financeira contra a Lavagem de Dinheiro e o Financiamento do Terrorismo (FATF/GAFI) e a OMC, por exemplo. Em termos políticos, a agenda do BRICS não vem sendo de confrontação, mas sim a de reivindicar "um lugar à mesa" junto às potências ocidentais, para obter mais voz e uma maior participação dentro das instituições já existentes (GARCIA; BOND, 2015).

Essas questões nos remetem às relações entre BRICS e ordem mundial. Se, por um lado, nota-se no BRICS uma agenda reformista, de crítica à ordem mundial vigente e dos ajustes feitos a partir do fim da II Guerra Fria, por outro lado, é fundamental perceber que esses países se encontram integrados à ordem mundial, tendo seu processo de "emergência" intimamente conectado aos processos de globalização neoliberal. Isso é importante, pois ajuda a entender de maneira menos simplista certos rumos da conjuntura internacional, especialmente (mas não somente) no que tange aos dois grandes exemplos de adensamento institucional do BRICS, o NDB e o ACR. Embora sejam novos arranjos multilaterais intimamente conectados a uma estratégia chinesa mais ampla de financiamento de infraestrutura (RAMOS; VADELL, 2016), bem como a uma crítica corrente à estrutura das instituições de Bretton Woods (FMI e Banco Mundial), eles mesmos não se apresentam abertamente como uma alternativa contra-hegemônica (BRICS, 2015, "para"66). O ACR é particularmente interessante: no artigo 5 do Tratado para o Estabelecimento do Arranjo Contingente de Reservas dos BRICS, que trata do acesso das partes aos recursos do ACR, é afirmado que o acesso a $70 \%$ do máximo disponível para cada parte depende necessariamente "da existência de um acordo em curso entre o FMI e a Parte Requerente que envolva o compromisso do FMI 
de prover financiamento à Parte Requerente com base em condicionalidades, e o cumprimento pela Parte Requerente dos termos e condições do referido acordo" (MINISTÉRIO DAS RELAÇÕES EXTERIORES, 2014b, art. 5, d, ii, p.5). Ou seja, a legitimidade do FMI - e em última instância, do Sistema de Bretton Woods - é reafirmada desde a criação do ACR até a cúpula de Xiamen, quando se defendeu a necessidade de "promover uma cooperação mais próxima entre o FMI e o ACR" (BRICS, 2017, "para”30) 8 .

Dessa forma, faz cada vez mais sentido entender o BRICS não como um desafio coletivo à ordem mundial, mas, sim, como um arranjo conservative globalizer (KAHLER, 2013, 2016; GARCIA; BOND, 2015) que, nesse sentido, demanda, na verdade, uma reforma da ordem mundial, seja no sistema ONU (Conselho de Segurança, p. ex.), seja no Sistema de Bretton Woods. Isso ajuda a entender também certos processos causais associados às críticas de certos movimentos da sociedade civil ao BRICS, bem como a falta de diálogo explícito entre o arranjo e esses movimentos - diferente do que ocorre com o Foro Empresarial do BRICS ou o Conselho Empresarial do BRICS. Ou seja, em última instância, ajuda a entender os limites do BRICS como um caso de emergência alternativa9 ${ }^{9}$

\section{Considerações finais}

Os processos causais associados à emergência do BRICS apontam para esse como um modelo com caráter diferenciado em um contexto neoliberal (PIJL,2017), nitidamente: i) reafirmando o papel do Estado na alavancagem de empresas multinacionais (estatais ou privadas) e na condução de grandes projetos de infraestrutura e energia; ii) criando entraves à política de recurso à força liderada pelos EUA, em franco tensionamento com a governança estruturada a partir da ONU; e iii) projetando novos arranjos políticos e econômicos e criando novas instituições credoras, como é o caso do NDB e dos bancos nacionais de desenvolvimento dos países do BRICS.

Assim, se olharmos para a inserção do BRICS no sistema internacional "desde cima” - partindo da perspectiva da disputa entre os grandes poderes mundiais -,

8 Para uma análise mais detalhada do NDB e do ACR, ver Carvalho et al. (2015).

9 Embora não seja o foco do presente artigo, é importante, nesse caso, para entender tais relações entre Estado e sociedade civil no BRICS, entender as particularidades de seus respectivos processos de formação capitalista. Nesse sentido, uma interessante discussão é apresentada por Pijl, 2017. 
podemos observar tensões e desafios vindos desses países individualmente frente às potências tradicionais. Nesse sentido, podemos considerar que o BRICS busca acumular capacidades econômicas e políticas (que podem ser traduzidas em maior capacidade militar) frente às potências hegemônicas. Se, por sua vez, olharmos para as relações entre os países que compõem o BRICS de forma horizontal, enxergamos as convergências e disputas entre esses mesmos países, com as diferenças e desigualdades entre eles. Por fim, se enxergarmos o BRICS de forma vertical, compreendendo as relações do BRICS com outros países e regiões do Sul Global, podemos concluir que essas são relações de poder que se enquadram no marco mais amplo de acumulação capitalista, respondendo a uma lógica de disputa por recursos naturais, acesso a mercados e mão de obra cada vez mais barata e superexplorada. Nesse artigo, buscamos mostrar essas diferentes visões, partindo da identificação e análise de distintos mecanismos causais localizados em níveis distintos de análise.

Passada, então, mais de uma década, a grande questão que se coloca diz respeito aos rumos desse arranjo. Como visto, a conjuntura da geopolítica do capitalismo tem sido um mecanismo com impacto significativo no processo de evolução, adensamento institucional e de outreach do BRICS. Nesse sentido, tendo em vista os rumos do arranjo, a atual conjuntura internacional terá também impactos causais significativos na trajetória do BRICS. Deve-se ter em mente, assim, i) a real capacidade centrípeta do BRICS de gerar um polo de contraposição aos EUA sob a presidência de Donald Trump e, concomitantemente, ii) os impactos gerados pelas próprias mudanças políticas no âmbito dos países do BRICS - como no caso do Brasil, por exemplo. Certamente a direção e o rumo dos processos de adensamento institucional (especialmente, mas não exclusivamente, nas áreas de economia política - desenvolvimento internacional - e segurança internacional) e de outreach, bem como o espaço às demandas da sociedade civil, tendem a sofrer impactos dessas e de outras questões; ou seja, os desdobramentos e entrelaçamentos futuros desses processos causais podem apresentar duros testes para os avanços futuros do BRICS - em outras palavras, podem ser vistas como testes complementares da hipótese aqui apresentada acerca dos rumos do adensamento institucional do BRICS. Não obstante, essas são algumas das perguntas que podem iluminar pesquisas futuras a respeito do BRICS e de seu papel na ordem mundial daqui para frente. 


\section{Referências}

ABDENUR, A; FOLLY, M. O Novo Banco de Desenvolvimento e a institucionalização do BRICS. In: R. Baumann, et. al. BRICS: Estudos e documentos. Brasília: FUNAG, 2015, p. 79-214.

ANDREASSON, S., 2011. Africa's prospects and South Africa's leadership potential in the emerging markets century. Third world quarterly, 32(6), 2011, pp. 1165-1181. DOI: $10.1080 / 01436597.2011 .584725$

BANDYOPADHYAY, K. K. Civil society engagement in BRICS: Mere symbolism? PRIA. 28 de junho de 2017.Disponível em: https://pria.org/pria/?p=3196. Acesso em: 05.nov.2017.

BEACH, D.; PEDERSEN, R. B. Process-Tracing Methods: Foundations and Guidelines. Ann Arbor: University of Michigan Press. 2013.

BENNETT, A., Process tracing and causal inference. In: BRADY H. E; COLLIER, D. Rethinking social inquiry: Diverse tools, shared standards. $2^{\text {nd }}$ ed. Lanham: Rowman \& Littlefield, pp. 207-219, 2010.

BENNETT, A., 2013. The mother of all isms: causal mechanisms and structures pluralism in International Relations theory. European Journal of international relations, 19(3), pp. 459-481. DOI: 10.1177/1354066113495484, 2013.

BRICS INDIA: 2016. 8th Brics Summit: Building responsive, inclusive \& collective solutions. Goa. 15 outubro 2016. Disponível em: < http://brics2016.gov.in/content/ innerpage/8th-summit.php > . Acesso em: 28.abril.2016.

BRICS BUSINESS COUNCIL. Annual Report. 2013/2014. Disponível em: < http://arquivos. portaldaindustria.com.br/app/conteudo_18/2014/07/15/6862/BRICSBusiness CouncilAnnualReportDRAFT6-11JulySignature.pdf > . Acesso em: 28.abril.2017.

BRICS BUSINESS COUNCIL. Facing challenges, building confidence. Second Annual Report 2015-2016. Disponível em: < http://arquivos.portaldaindustria.com.br/app/ conteudo_18/2015/07/09/9148/BRICSRelatrioAnual.pdf > . Acesso em: 28.abril.2017.

BRICS BUSSINESS COUNCIL. Members of the Brazilian BRICS business council, 2016. Disponível em: < https://www.bricsbusinesscouncil.in/bbc-brazil.php > Acesso em 28.abril.2017.

CARVALHO, C. E., et all. O banco e o arranjo de reservas do BRICS: iniciativas relevantes para o alargamento da ordem monetária e financeira internacional. Estudos Internacionais, 3 (1), pp. 45-70, 2015.

CHERNOFF, F. 2007. Critical realism, scientific realism, and International Relations theory. Millennium: Journal of international studies, 35(2), pp. 399-407. DOI: $10.1177 / 03058298070350021701$

CIVIL BRICS. 2015. Disponível em: < http://www.civilbrics.ru/en/ > . Acesso em: 28.abr.2017. 
COOPER, J. M. Russia as a BRIC: Only a dream? European Research Working Paper Series, n. 13. Birmingham. Centre for Russian and East European Studies, University of Birmingham, 2006.

DANÍVOLA, G. ¿Cómo va a funcionar el Nuevo Banco de Desarrollo de los BRICS? RBTH. 9.jul.2015. Disponível em: < http://es.rbth.com/economia/2015/07/09/como_va_a_ funcionar_el_nuevo_banco_de_desarrollo_de_los_brics_50813.html >. Acesso em: 10.mai.2016.

FORTESCUE, S. The BRICS and Russia. In: LO,V. I.; HISCOCK M. The rise of the BRICS in the global political economy: Changing paradigms? Cheltenham: Edward Elgar, 2014. GARCIA, A.; BOND, P. Introduction. In: BOND, P.; GARCIA, A. BRICS: An anti-capitalist critique. Sunnyside: Jacana. Pp. 1-14, 2015.

GRAMSCI, A. Selections from the Prison's Notebooks. Edited and translated by Quintin Hoare and Geoffrey Nowell Smith. New York: International Publishers, 1971.

JANS, 'Brics-from-Below' - counter summit hosted in Durban. EarthLife Africa, 20.mar.2013. Disponível em: < http://earthlife.org.za/2013/03/brics-from-below-counter-summithosted-in-durban/ > . Acesso em: 28.abr.2017.

KAHLER, M. Rising powers and global governance: negotiating change in a resilient status quo. International Affairs, 89 (3). pp. 711-729, 2013. DOI: 10.1111/1468-2346.12041.

KAHLER, M. Conservative Globalizers: Reconsidering the Rise of the Rest. World politics review, 2.fev. 2016. Disponível em: < http://www.worldpoliticsreview. com/articles/17840/conservative-globalizers-reconsidering-the-rise-of-the-rest $>$. Acesso em: 10.mai.2016.

KHALID, A. The power of the BRICS in world trade and growth, analysing the macroeconomic impacts within and across the bloc. In: LO,V. I.; HISCOCK M The rise of the BRICS in the global political economy: Changing paradigms? Cheltenham: Edward Elgar, 2014.

MACFARLANE, N. S. The "R" in BRICs: Is Russia na emerging power? International Affairs, 82 (1), pp.41-57, 2006. DOI: 10.1111/j.1468-2346.2006.00514.x

MEDEIROS, M. A. et all. Cooperação para autonomia? Explicando o paradoxo da política externa brasileira para a Unasul. Rev. Sociol. Polit. 25 (61). pp. 97-123, 2017. DOI: $10.1590 / 1678-987317256106$.

MELLO, P. C. Brasil ficará de fora do Conselho de Segurança da ONU ao menos até 2033. Folha de São Paulo. 17.mar. 2017. Disponível em: < http://www1.folha.uol.com.br/ mundo/2017/03/1867280-brasil-ficara-de-fora-do-conselho-de-seguranca-da-onu-aomenos-ate-2033.shtml > . Acesso em: 28.abr.2017.

MINISTÉRIO DAS RELAÇÕES EXTERIORES DO BRASIL. I Cúpula: Declaração conjunta. Ecaterimburgo. 16.junho/2009. Disponível em: http://brics.itamaraty.gov.br/pt_br/ categoria-portugues/20-documentos/73-primeiro-declaracao. Acesso em: 10 maio 2016. 
MINISTÉRIO DAS RELAÇÕES EXTERIORES DO BRASIL.II Cúpula: Declaração. Brasília. 15.abril/2010. Disponível em: < http://brics.itamaraty.gov.br/pt_br/categoria-portugues/ 20-documentos/74-segunda-declaracao-conjunta > . Acesso em: 10 maio 2016.

MINISTÉRIO DAS RELAÇÕES EXTERIORES DO BRASIL III Cúpula: Declaração e Plano de Ação de Sanya. Sanya. 14.abril/2011. Disponível em: < http://brics.itamaraty.gov. br/pt_br/categoria-portugues/20-documentos/75-terceira-declaracao-conjunta > . Acesso em: 10 maio.2016.

MINISTÉRIO DAS RELAÇÕES EXTERIORES DO BRASIL IV Cúpula: Declaração e Plano de Ação de Nova Delhi. Nova Delhi. 29.março/2012. Disponível em: < http://brics. itamaraty.gov.br/pt_br/categoria-portugues/20-documentos/76-quarta-declaracaoconjunta. Acesso em: 10 maio 2016.

MINISTÉRIO DAS RELAÇÕES EXTERIORES DO BRASIL V Cúpula: Declaração e Plano de Ação de eThekwini. Durban. 27.março 2013. Disponível em: http://brics.itamaraty. gov.br/pt_br/categoria-portugues/20-documentos/77-quinta-declaracao-conjunta > . Acesso em: 10 maio 2016.

MINISTÉRIO DAS RELAÇÕES EXTERIORES DO BRASIL. VI Cúpula: Declaração e Plano de Ação de Fortaleza. Fortaleza. 15.julho 2014. BRICS, art. 5, d, ii, p.5. Disponível em: < http://brics6.itamaraty.gov.br/pt_br/categoria-portugues/20-documentos/224vi-cupula-declaracao-e-plano-de-acao-de-fortaleza > . Acesso em: 10 maio 2016.

MINISTÉRIO DAS RELAÇÕES EXTERIORES DO BRASIL. VII Cúpula: Declaração de Ufá. Ufá. 9 julho 2015. Disponível em: < http://brics.itamaraty.gov.br/pt_br/categoriaportugues/20-documentos/252-vii-cupula-do-brics-declaracao-de-ufa > . Acesso em: 10.maio. 2016.

MINISTÉRIO DAS RELAÇÕES EXTERIORES DO BRASIL. Tratado para o Estabelecimento do Arranjo Contingente de Reservas dos BRICS. 2014.Disponível em: < http://brics. itamaraty.gov.br/images/ACR \% 20portugues.pdf > . Acesso em: 28.abril.2017

MINISTRY OF EXTERNAL AFFAIRS GOVERNEMENT OF INDIA Brics Bussiness Council. 2016b. Participating companies. Disponível em: < http://www.bricsbusinesscouncil. in/confirmed-delegates.php > . Aceso em: 28.abril.2017.

MINISTRY OF EXTERNAL AFFAIRS GOVERNEMENT OF INDIA. Agreements between BRICS Develoment Banks, Nova Delhi. 29.março 2012. Disponível em: < http://www. brics.utoronto.ca/docs/120329-devbank-agreement.pdf > . Acesso em: 10 maio 2016 MINISTRY OF FOREIGN AFFAIRS OF THE PEOPLE'S REPUBLIC OF CHINA. Xiamen Declaration. Brics 2017 China. Disponível em: 4 de setembro de 2017. < https:// www.brics2017.org/English/Documents/Summit/201709/t20170908_2021.html. > Acessado em: 05.novembro.2017.

NEELAKANTAN, S. India used Brics-Bimstec summit to outmanoeuvre Pakistan, Chinese media says. The Times of India. 19.out. 2016. Disponível em: < http://timesofindia. 
indiatimes.com/india/India-used-Goa-Brics-meet-to-outmanoeuvre-Pakistan-Chinesemedia-says/articleshow/54933030.cms > . Acesso em: 10.mai.2016.

PAUTASSO, D.; ADAM, G.; LIMA, B. R. A política externa da Rússia diante da crise na Síria. Tensões mundiais. 11 (21), pp. 147-168, 2015.

PEOPLE'S FORUM ON BRICS. The New Development Banks: Why AIIB and NDB should be monitored. 2016. Disponível em: < https://peoplesbrics.org/2016/10/07/thenew-development-banks-why-aiib-and-ndb-should-be-monitored/ > . Acesso em: 28.abr.2017.

PEOPLE'S FORUM ON BRICS. Building Solidarities for Social, Economic and Environmental Justice: Goa Declaration of the People's Forum on BRICS. 14.out. 2016. Disponível em: < https://peoplesbrics.org/2016/10/24/goa-declaration-of-the-peoples-forumon-brics/ > . Acesso em: 28.abr.2017.

PIJL, K. The Eurasian Union and the BRICS under attack. Paper for the conference, Regional Perspectives for China and its Neighbours, Confucius Institute, Leiden University, 2017.

RAMOS, L. et all. Objetivos, contradições e atuação da África do Sul no G20. Meridiano 47, 13(132), pp. 46-52, 2012. DOI: 10.20889/7131.

RAMOS, L.; VADELL, J. Asian Infrastructure Investment Bank (AIIB) and beyond: finance, infrastructure and the seductive claws of the Chinese dragon. Artigo apresentado no congresso da International Studies Association, Atlanta, 2016.

SAJJANHAR, A. Brics, Bismtec and Anti-terrorism: what did India accomplish?. The Diplomat. 25.out.2016 Disponível em: < http://thediplomat.com/2016/10/bricsbimstec-and-anti-terrorism-what-did-india-accomplish/ > . Acesso em: 28.abril.2017. SEVERO, L. Movimentos sociais debatem Os BRICS na perspectiva dos povos. 15.jul.2014. Disponível em: < http://www.rebrip.org.br/noticias/movimentos-sociais-debatemos-brics-na-perspectiva-dos-povos-624d/ > . Acesso em: 28.abril.2017.

THE BRICS POST BRICS Bank to lend \$2.5 billion in 2017. 17.outubro 2016. Disponível em: < http://thebricspost.com/brics-bank-to-lend-2-5-billion-in-2017/\#.WATH9UrIdU > . Acesso em: 28.abril.2017.

WAISBICH, T. Diverse voices: A brief account on the civil society spaces at the margins of the $8^{\text {th }}$ BRICS Summit in India: BRICS 'civilised' and 'popular' spaces. Sexuality Police watch. 29.dezembro.2016. Disponível em: < https://sxpolitics.org/diversevoices-a-brief-account-on-the-civil-society-spaces-at-the-margins-of-the-8th-bricssummit-in-india/16206 > . Acesso em: 29.abril.2017.

WIGHT, C. Agents, structures and international relations: Politics as ontology. Cambridge: Cambridge University Press, 2006. 